\title{
O PROFETA E O LIVRO SAGRADO DO LIVRE MERCADO: HAYEK E O CAMINHO DA SERVIDÃO NOS ESTADOS UNIDOS
}

\author{
The Prophet and the Free-Market's Holy Book: Hayek and \\ The Road to Serfdom in the United States
}

\begin{abstract}
Gabriel da Fonseca Onofre*
Resumo: $\mathrm{O}$ artigo analisa a importância de Hayek e seu livro O Caminho da Servidão para o fortalecimento de uma rede internacional a favor das ideias de defesa do capitalismo de livre mercado. Nos Estados Unidos, as elites políticas, econômicas e intelectuais, insatisfeitas com o programa do New Deal, não conseguiam avançar uma agenda econômica crítica ao programa do presidente Franklin Roosevelt nos anos 1930. Em meados da década seguinte, o lançamento e a popularidade do livro do intelectual austríaco serviram como inspiração e referência para novas iniciativas críticas às políticas do governo democrata. Neste sentido, com o apoio dos empresários, Hayek teve um papel-central no desenvolvimento de uma comunidade de indivíduos e instituições (think tanks) responsáveis pelo avanço das ideias do liberalismo econômico no país.

Palavras-chave: Hayek - liberalismo econômico - New Deal
\end{abstract}

\begin{abstract}
The present article traces the origins of free-market ideas'success in the United States. In 1945, a book called The Road to Serfdom appeared in the United States. America's reception of Hayek's book was impressive. Some of the principles advocated in the book were: limited government, free markets, private property, and individual freedom. This article analyzes The Road to Serfdom's importance for the intellectual and political history of the conservative movement in America.
\end{abstract}

Keywords: Hayek - classical liberalism - New Deal

New ideas start among a few and gradually spread until they become the possession of a majority who know little of their origin.

(Friedrich Hayek)

No segundo semestre de 1945, nos Estados Unidos, predominava um sentimento de otimismo e euforia entre muitos norte-americanos, empolgados com a vitória das forças aliadas sobre o fascismo na Europa e na Ásia. Contudo, esse entusiasmo com o desfecho da segunda guerra mundial não era compartilhado por muitos conservadores do país. Se, por um lado, a ameaça do nazismo não existia mais e se encerrava a maior guerra da história moderna, por outro lado, outro problema surgia tão ou mais ameaçador sob a perspectiva desses indivíduos: a expansão do comunismo e dos Estados de Bem-Estar Social.

Nesta conjuntura, um livro tornou-se sensação no país. O Caminho da Servidão do filósofo austríaco Friedrich Hayek alcançou um número de vendas impensável para uma obra de economia e de não ficção. Este que se tornou um dos mais famosos manifestos de defesa do capitalismo

\footnotetext{
* Professor do Colégio Pedro II, atuando como professor da Educação Básica e da Pós-Graduação. Possui Doutorado em História pela Universidade Federal Fluminense (UFF). E-mail: gabriel.onofre@outlook.com
} 
liberal contra o avanço das ideias do keynesianismo e do socialismo possui um papel destacado na formação do movimento conservador dos Estados Unidos.

O objetivo deste artigo é demonstrar a importância de Hayek e seu O Caminho da Servidão para o fortalecimento de um movimento internacional em defesa das ideias do liberalismo econômico. Veremos ainda como nos Estados Unidos as ideias do pensador austríaco forneceram uma base intelectual importante para o até então incipiente e frágil movimento conservador de oposição ao New Deal. Por fim, analisaremos como a figura de Hayek, com o apoio financeiro das elites econômicas norte-americanas, tornou-se fundamental para o desenvolvimento de uma rede de indivíduos - intelectuais, jornalistas e empresários - e de instituições em defesa das ideias do livremercado ${ }^{1}$.

\section{Antecedentes}

O lançamento do livro O Caminho da Servidão de Hayek, em 1944, marcou um ponto de virada para os críticos do New Deal nos Estados Unidos. Até esse momento, não havia um movimento conservador forte e organizado no país. A hegemonia das ideias de apoio a um Estado mais atuante nos assuntos econômicos e sociais contrastava com a fragilidade do campo que defendia um capitalismo mais liberal. A razão para isso era bastante evidente: os Estados Unidos ainda se recuperavam do desastre econômico e social da Grande Depressão. E, por isso, a necessidade de um governo forte para combater os efeitos da crise ainda encontrava muitos adeptos no país.

Na década de 1930, o presidente Franklin Delano Roosevelt lançou um conjunto de medidas econômicas e sociais conhecidas como New Deal, com o objetivo de combater a crise que assolava o país. Contra o programa, mobilizaram-se ações políticas, intelectuais e empresariais, como a American Liberty League, a National Association of Manufacturers (NAM) e a campanha do candidato republicano Wendell Wilkie em 1940.

Em junho de 1934, em Nova Iorque, por iniciativa de uma das famílias mais ricas do país, surgiu a American Liberty League. A organização, capitaneada pelo clã Du Pont, tinha como objetivo reunir empresários preocupados com as medidas políticas e econômicas adotadas pelo presidente Roosevelt. $\mathrm{Na}$ reunião de fundação, decidiu-se que o nome da nova entidade não faria menção às empresas ou aos empresários para não ser acusada de ser uma organização de defesa dos interesses dos mais ricos. O nome deveria remeter à ideia de defesa da constituição e das liberdades democráticas do país. A associação de executivos de grandes e médias empresas buscava se apresentar como apartidária, reunindo o apoio de democratas e republicanos e contando com a participação de organizações como a American Legion e "mesmo a Ku Klux Klan". A pretensão da American Liberty League de se tornar um movimento de massas, no entanto, não vingou. Segundo Kim Phillips-Fein, "mais da metade dos recursos da Liga no ano de 1935 vieram de menos de duas dúzias de banqueiros, industriais e empresários, e membros da família Du Pont contribuíram com 30\% do total" (PHILLIPS-FEIN, 2009, p. 10-12). Além disso, com a imagem prejudicada pela simpatia de vários membros da Liga pelo regime de Mussolini e a campanha bem-sucedida dos democratas e dos trabalhadores que associaram a organização à defesa dos privilégios dos mais ricos, apelidando-a de "Millionaires Union", a iniciativa durou pouco. Seis anos depois da sua criação, a American Liberty

\footnotetext{
1 Para analisar a trajetória de Hayek e a constituição de uma rede internacional de indivíduos e instituições ao seu redor, com destaque para a Sociedade Mont Pelerin (SMP), sobre a qual falaremos mais a frente, utilizamos os documentos presentes nos arquivos do próprio Hayek, da SMP e de outros intelectuais e empresários, disponíveis no Hoover Institution, na Universidade de Stanford.
} 
League dissolveu-se.

Houve outras iniciativas de empresários contra o New Deal no período. Algumas delas antigas, apenas com novas roupagens. Esse é o caso da National Association of Manufacturers (NAM), formada no final do século anterior. A associação tornou-se a principal organização empresarial de oposição ao New Deal e ao movimento sindical. Na segunda metade dos anos 1930, a organização investiu em uma intensa campanha de ataque às políticas de Roosevelt com a produção de propagandas políticas, programas de rádio e filmes. O entendimento da NAM era que a sociedade não compreendia a importância das empresas para a economia e para o bem-estar geral e que os sindicatos e políticos favoráveis ao New Deal dominavam o debate público. Veremos a seguir que esse diagnóstico e solução estarão no centro do debate do movimento conservador na década de 1940: para combater o New Deal, era necessário ganhar no campo das ideias.

Todavia, essas iniciativas empresariais tinham pouco terreno para ser bem-sucedidas. Em um país arrasado pela crise e pela fome, associações de empresários em defesa do capitalismo eram facilmente associadas com privilégios e defesa do status quo.

Houve ainda oposição política e intelectual ao programa de Roosevelt. A campanha do candidato republicano Wendell Willkie, em 1940, desafiou a candidatura do atual presidente que buscava o terceiro mandato. Como toda corrida eleitoral, vários temas foram objetos de disputa. Naquele momento, a posição sobre a participação ou não do país na Segunda Guerra Mundial dominou boa parte da campanha. Porém, mais do que a disputa sobre o envolvimento ou não do país no conflito, interessa-nos aqui a defesa do capitalismo liberal e as críticas ao New Deal empreendidas pela campanha de Wilkie. Em um dos seus atos de campanha, o republicano revelou que "sou empresário e tenho orgulho disso. Fazer negócios é nosso modo de vida, nossa realização, nossa glória" (BURNS, 2009, p. 54). A mensagem-central da campanha de Wilkie era de crítica às políticas econômicas e sociais do presidente democrata e de defesa do capitalismo de livre empresa. Importante dizer que naquele momento o programa de Roosevelt ainda não tinha tirado o país da Grande Depressão e a taxa de desemprego beirava $15 \%$. No entanto, a conjuntura internacional delicada, com as tropas nazistas marchando na Europa e o agravamento dos conflitos entre alemães e norte-americanos em águas internacionais, reforçava o apelo da campanha democrata sobre a necessidade de não se promover grandes mudanças políticas no momento. E diante da popularidade de Roosevelt, Wilkie foi derrotado.

Entre os poucos intelectuais reconhecidos que se opuseram publicamente ao New Deal nesses anos, destacaram-se Albert Jay Nock e H.L Mencken. O primeiro, autor de Our Enemy, the State e fundador da revista The Freeman, fazia uma apaixonada crítica ao Estado e pregava em defesa do individualismo e dos livres mercados. Após sua morte, em 1945, tornou-se uma personalidade influente para o movimento conservador do pós-guerra. O segundo, jornalista e crítico literário, fundou a revista American Mercury e através dela defendia o capitalismo liberal e atacava as políticas de Roosevelt. De acordo com Jennifer Burns, Nock e Mencken foram os primeiros a se identificarem como libertários (libertarians ${ }^{2}$ ), no sentido de defensores de um governo bastante reduzido (BURNS, 2009, p. 48). No mesmo período, mas ainda uma personalidade desconhecida, Ayn Rand

\footnotetext{
20 termo libertário (libertarian) usado aqui não é o tradicionalmente associado à esquerda, que aponta para a defesa do fim do capitalismo e do Estado e para a coletivização da propriedade. Nos anos 1930 e 1940, nos Estados Unidos, "libertarianism" surgiu para nomear os defensores do livre-mercado que não usavam mais o termo "liberal", associado agora às políticas pró-New Deal. Entre as figuras proeminentes que usaram pioneiramente o termo nos Estados Unidos, estão Albert Jay Nock e H.L. Mencken. Vale dizer, contudo, que foi apenas na década de 1950 que esse uso da palavra "libertário" ganhou força no debate público.
} 
publicou sua primeira obra: We the living. O romance possuía uma mensagem bastante clara, bem no estilo randiano: governos grandes produzem um sistema social perverso que esmaga as virtudes dos seres humanos; virtudes identificadas pela autora com o individualismo e o auto-interesse. Apesar desses exemplos, não havia muitos intelectuais produzindo críticas ao New Deal, menos ainda em defesa de um capitalismo mais liberal ${ }^{3}$.

Importante dizer que o New Deal, mais do que um programa de reformas econômicas e sociais, era o reflexo do ambiente político e social do país. Arrasados pelo choque econômico de 1929 e insatisfeitos com as respostas do liberalismo clássico, movimentos populares e de trabalhadores pressionaram por uma nova concepção de Estado, capaz de resolver o drama que atingia o país. Como explica a historiadora Lizabeth Cohen, o New Deal foi obra dos indivíduos que por toda a nação responderam à Grande Depressão com greves, protestos e outras iniciativas políticas em favor de uma nova postura do Estado, pressionando assim Washington a rejeitar o programa econômico do capitalismo de laissez-faire então vigente (COHEN, 1990). Dessa forma, diante dessa base social forte e atuante, as iniciativas frágeis e isoladas de rejeição ao New Deal nos anos 1930 tiveram pouca chance de sucesso. Mas isso estava para mudar.

\section{Friedrich Hayek}

$\mathrm{Na}$ Grã-Bretanha, os críticos do crescimento das atribuições do Estado não estavam mais otimistas que seus aliados do outro lado do Atlântico. Na eleição de 1945, os trabalhistas varreram Winston Churchill do Palácio de Westminster. O novo primeiro-ministro, Clement Attlee, prometia uma ampla reforma social. A nacionalização das minas, do transporte de cargas, de ferrovias e de prestadoras de serviços públicos e o provimento de assistência médica eram o centro das propostas econômicas do Partido Trabalhista inglês. A construção de um Estado de Bem-Estar Social passou a figurar, assim, no horizonte político de Downing Street.

Em reação a esse contexto político e econômico, Friedrich Hayek escreveu $O$ Caminho da Servidão. Seu livro menos ambicioso e acadêmico, tornou-se um sucesso de público. Dedicado em seu prefácio aos socialistas britânicos, Hayek resumia a obra como um esforço intelectual fruto das suas preocupações com os rumos da Europa do pós-1945. Para o filósofo austríaco, o aumento sem precedentes das atribuições do Estado durante a guerra era motivo de grande preocupação. Principalmente porque muitos governos, influenciados pela experiência da União Soviética, uma das forças vitoriosas do conflito, recorriam ao planejamento econômico como principal mecanismo de administração das economias do pós-guerra e para Hayek aí estava a semente do autoritarismo. Para ele, o planejamento econômico levava à ditadura, uma vez que o controle centralizado da economia com um Estado forte e atuante produziria uma elite política cada vez mais poderosa e ameaçadora das liberdades democráticas. A tese principal do livro era que o controle das decisões econômicas nas mãos do governo resultava na supressão das liberdades políticas e sociais. ${ }^{4} \mathrm{~A}$ partir

\footnotetext{
3 Houve ainda a oposição da Suprema Corte ao New Deal. Em 1935 e 1936, a Corte bloqueou diversas legislações propostas pelo governo. Em reação a isso, no início de 1937, Roosevelt propôs expandir o tamanho da Suprema Corte com o objetivo de alterar sua composição. Se aprovada, a iniciativa permitiria ao presidente nomear seis juízes de imediato, o que poderia favorecê-lo nas futuras decisões da Corte. A manobra, contudo, não foi adiante, uma vez que enfrentou resistência não apenas dos republicanos, mas também da imprensa, de juristas e mesmo de democratas.

${ }^{4}$ Importante mencionar que Hayek ressalta que não são todas as intervenções do Estado que conduzem ao autoritarismo, mas apenas as interferências que fazem parte de uma concepção de Estado baseada no planejamento centralizado.
} 
desse raciocínio, Hayek concluiu que as políticas keynesianas do pós-guerra e o socialismo representavam a mesma ameaça que o fascismo às liberdades individuais básicas. E, por isso, o contexto imediato do final da guerra não era motivo de comemoração, mas de preocupação e de atenta vigilância. Mas antes de falarmos do sucesso da obra, uma pausa para algumas palavras sobre seu autor.

A história de vida de Hayek confunde-se com a história do século XX. Friedrich August von Hayek nasceu em Viena, capital do Império Austro-Húngaro, em 8 de maio de 1899. Faleceu em 23 de março de 1992, na cidade de Freiburg na Alemanha. Seus mais de noventa anos de vida foram dedicados à produção intelectual, especialmente às críticas ao intervencionismo do Estado e à defesa do livre mercado. Hayek tornou-se, assim, o mais célebre oponente da economia keynesiana no pós-guerra. Mas, apenas no final de sua vida, viu suas ideias tornarem-se hegemônicas.

Nascido no seio da aristocracia austríaca decadente, Hayek assistiu à guerra e à inflação destruírem sua classe social. A fortuna da sua família deteriorou-se no período. A nova situação influenciou a escolha da sua formação profissional. Inicialmente interessado em estudar psicologia, abandonou a ideia por entender que a área não lhe oferecia perspectiva de emprego. Assim, escolheu o curso de Economia e Jurisprudência na Universidade de Viena. Em 1921, recebeu o doutorado em sua área de formação. Dois anos depois, veio seu segundo doutorado, agora em Ciência Política.

$\mathrm{Na}$ sua juventude, o ícone do liberalismo econômico flertou com o socialismo. Eram os anos da "Viena vermelha", quando os sociais-democratas austríacos governavam a cidade. Mas a aproximação de Hayek com as ideias de Marx foi interrompida pela presença de Ludwig von Mises. As críticas econômicas da obra Socialismo e a participação por sete anos no seminário Privatseminar, ministrado por Mises, são responsáveis pela mudança de Hayek em direção às ideias do livre mercado, especialmente em sua versão da Escola Austríaca5 ${ }^{5}$.

Em 1931, Hayek emigrou para a Inglaterra para trabalhar na London School of Economics. O convite para trabalhar como professor-visitante, em Londres, foi feito por Lionel Robbins, impressionado com o artigo de Hayek The Paradox of Saving. A contratação de Hayek fez parte de uma estratégia de fortalecimento da London School, que desejava formar um grupo de acadêmicos capaz de rivalizar no debate econômico com a Universidade de Cambridge, de Keynes e seus seguidores.

Nesta década, marcada pela crise do liberalismo político e econômico, Hayek começou a ganhar notoriedade por seus escritos em defesa dos livres mercados. O economista austríaco escreveu importantes trabalhos sobre taxas de câmbio, teoria do capital e reforma monetária. Mas foi apenas com o lançamento de O Caminho da Servidão, em 1944, que Hayek tornou-se internacionalmente reconhecido.

\section{O sucesso de "O Caminho da Servidão"}

Lançado em março de 1944, na Inglaterra, a primeira edição do livro esgotou-se em um mês. O impacto do livro se refletiu também nos debates do parlamento britânico. "Caminho da Servidão" virou um slogan usado pelos conservadores para acusar as propostas políticas dos trabalhistas $^{6}$. Traduzido para outros idiomas, a obra teve influência destacada também em outros

\footnotetext{
5 Entrevista de Hayek em Nobel prize-winning economist oral history transcript. Projeto do Programa de História Oral da Universidade da Califórnia, versão EPUB, p. 324.

6 Cartas de John Scoop para Fritz Machlup, em 7 de agosto de 1944, e Fritz Machlup para John Scoop, em 2 de agosto de 1944. Arquivo Hayek Papers. Caixa 36. Pasta 17.
} 
países. Neste artigo, examinaremos alguns dos seus impactos nos Estados Unidos.

$\mathrm{Na}$ terra do New Deal, o sucesso foi ainda maior. Em poucos meses, esgotaram-se duas edições. No final de 1944, havia a expectativa de atingir a marca de 35 mil cópias vendidas ${ }^{7}$. Meses depois, a popular revista Reader's Digest produziu uma versão condensada do livro. O novo formato impulsionou ainda mais as vendas, levando o sucesso de $O$ Caminho da Servidão a outro patamar. Em abril de 1945, a Reader's Digest distribuiu seu novo livro do mês. Mais de um milhão de cópias invadiram os lares americanos, popularizando Hayek no país. A própria revista se impressionou com o número de vendas. Seu editor, Stanley High, escreveu para Hayek se dizendo surpreso com o impacto do livro, que passou a pautar o debate intelectual dos Estados Unidos. Em sua carta, declarou que sua revista "há muito tempo não produzia uma publicação tão significativa"8.

E na esteira das vendas, diferentes universidades norte-americanas começaram a convidar Hayek para dar palestras. Nas palavras de um observador da época: "raras vezes um livro de economia e não ficção tornou-se tão popular em tão pouco tempo” (NASH, 2006, p.7). O livro visto retrospectivamente como um grande sucesso enfrentou, contudo, dificuldades para conseguir uma editora nos Estados Unidos. Sobre isso, Hayek escreveu que não se surpreendeu quando o livro foi recusado pelas três primeiras editoras, pois "pensou pouco no país ao escrever sua obra" (HAYEK, 1967). Apesar de elaborado a partir dos eventos políticos europeus, o sucesso nos Estados Unidos demonstrou que o livro dialogava com o debate político e respondia aos interesses de parte do público do país.

Como vimos, até o momento, não havia um movimento estruturado de defensores do livre mercado no país. As iniciativas de oposição ao crescimento das atribuições do Estado eram restritas e pouco eficientes. O Caminho da Servidão fornecia uma base intelectual, um prestígio acadêmico e uma popularidade que a direita americana não possuía até então. A mensagem de Hayek, ao longo do livro, referia-se ao poder das ideias (power of ideas), tema caro ao intelectual austríaco nas suas produções seguintes. Segundo ele, ideias ruins produzem desastre econômico e autoritarismo. E, por isso, seu livro mais do que uma tese acadêmica, é um manifesto político contra os rumos dos governos democráticos do pós-guerra.

Veremos, agora, as duas razões para a importância de Hayek na formação de um movimento liberal clássico e conservador nos Estados Unidos: a primeira, resultado da mensagem do livro; e a segunda, efeito da rede constituída a partir da publicação da sua obra.

\section{A mensagem}

George Nash, um dos maiores estudiosos do movimento conservador dos Estados Unidos, aponta dois motivos para o sucesso do livro de Hayek no país. O primeiro resulta da publicação de sua versão condensada pela Reader's Digest. A revista, bastante popular, ajudou a difundir a obra no país. O segundo deve-se à crítica elogiosa escrita no New York Times Book. Review. Além de ter recebido um espaço de grande destaque no jornal, o escolhido para avaliar o novo livro foi Henry Hazzlitt, fervoroso defensor do capitalismo liberal. A crítica não poderia ser mais favorável ${ }^{9}$ (NASH, 2009, p. 51).

\footnotetext{
7 Carta de Fritz Machlup para Hayek, em 19 de outubro de 1944. Arquivo Hayek Papers. Caixa 36. Pasta 17.

8 Carta de Stanley High para Hayek, em 18 de junho de 1945. Arquivo Hayek Papers. Caixa 101. Pasta 10.

9 Henry Hazlitt (1894-1993) foi um economista e jornalista estadunidense que trabalhou em diversos periódicos como The New York Times e Newsweek. Tornou-se famoso com o livro Economics in One Lesson, de 1946, que vendeu mais de um milhão de cópias.
} 
Ainda que estes tenham sido fatores importantes para o sucesso do livro, defendemos neste artigo outro motivo como mais preponderante: a mensagem moderada da obra. O Caminho da Servidão é, ao mesmo tempo, um manifesto contrário ao socialismo e ao capitalismo keynesiano e uma defesa da reformulação do programa liberal clássico. Diferentemente do Hayek dos anos 1960 e 1970, quando o autor radicalizou sua defesa do livre-mercado, com propostas como a emissão privada de moeda, neste livro, o autor propõe uma renovação do liberalismo clássico que o afastasse do laissez-faire do final do século XIX e o protegesse das investidas do socialismo e do keynesianismo.

Defendemos aqui que é esta proposta de reformulação do liberalismo clássico, com a defesa de um papel atuante, embora limitado, do Estado em certas áreas que tornou possível o sucesso do livro nos Estados Unidos. Afinal, em meados dos anos 1940, com o país ainda se recuperando da crise econômica e com um grande temor de retorno da Grande Depressão, a defesa radical do livre-mercado dificilmente prosperaria. Basta vermos que, no mesmo ano, Ludwig von Mises publicou Omnipotent Government: The Rise of the Total State and Total War, uma crítica ácida ao Estado e uma defesa radical do laissez-faire. Esse livro, considerado uma obra-prima pelos defensores do liberalismo econômico da chamada Escola Austríaca, foi bastante criticado à época, mesmo entre defensores do livre mercado, segundo Fritz Machlup. Em carta para Hayek, o economista escreveu que evitava falar com Mises porque não sabia o que dizer sobre seu novo livro, que o deixou "pelo que leu até o momento triste"10. A opinião negativa seria compartilhada, de acordo com Machlup, por outros liberais clássicos que "não acharam nada de bom no livro, é apenas bem escrito e interessante" ${ }^{\prime 1}$.

O "caminho da servidão" é a metáfora de Hayek para o destino autoritário das democracias modernas baseadas em um Estado grande e planificador. Mas a essa direção, o autor opôs o "caminho abandonado" do individualismo extremado e da defesa radical do livre-mercado. Em sua proposta de reformulação do liberalismo clássico, escreveu:

Os princípios básicos do liberalismo [econômico] não contêm nenhum elemento que o faça um credo estacionário, nenhuma regra fixa e imutável. O princípio fundamental segundo o qual devemos utilizar ao máximo as forças espontâneas da sociedade e recorrer o menos possível à coerção pode ter uma infinita variedade de aplicações. Há, em particular, enorme diferença entre criar deliberadamente um sistema no qual a concorrência produza os maiores benefícios possíveis, e aceitar passivamente as instituições tais como elas são. Talvez nada tenha sido mais prejudicial à causa liberal do que a obstinada insistência de alguns liberais em certas regras gerais primitivas, sobretudo o princípio do laissez-faire. Contudo, de certa maneira, essa insistência era necessária e inevitável ${ }^{12}$. (HAYEK, 1990, p. 42)

No lugar do "caminho da servidão" e do "caminho abandonado", Hayek propôs "a regra da lei" (The Rule of Law) na qual o Estado possui certas funções, mas que "todas as suas ações são balizadas por regras fixadas e anunciadas antecipadamente", dispostas a "promover a competição e o funcionamento da sociedade livre” (HAYEK, 1990, p.55-63). Nesse sistema, algumas políticas

10 Carta de Fritz Machlup para Hayek, em 24 de agosto de 1944. Arquivo Hayek Papers. Caixa 36. Pasta 17.

11 Carta de Fritz Machlup para Hayek, em 2 de agosto de 1944. Arquivo Hayek Papers. Caixa 36. Pasta 17.

12 Nesta citação, Hayek usa o termo "liberal" para designar os princípios básicos e os defensores do liberalismo econômico. É o uso como fazemos no português e no debate político brasileiro. Mas vale dizer que, nos Estados Unidos, "liberal”, a partir da década de 1930, passou a fazer referência ao projeto de apoio a um papel do Estado mais ativo na economia, como nas propostas do New Deal. Ao longo do artigo, optamos por usar "defensores do livre-mercado" ou "liberais clássicos" para se referir aos partidários do capitalismo liberal. 
como a limitação da jornada de trabalho e as regras de seguridade social seriam aceitáveis. Concessões que Hayek fez nos anos 1940 e que abandonou décadas depois. Inaceitáveis para Mises, já nesse período, é bom dizer.

É importante frisar que mais do que um livro direcionado a uma reformulação do programa do liberalismo clássico, Hayek escreveu um manifesto contra o socialismo e o capitalismo com forte presença do Estado. $\mathrm{O}$ autor começou sua análise estabelecendo que a diferença entre defensores do liberalismo econômico e socialistas estava nos métodos empregados e não nos fins específicos de suas políticas. Para o filósofo, a busca por ideais como justiça social, igualdade e segurança seria compartilhado também pelos advogados do livre mercado. Sendo assim, o que diferenciava os dois grupos não seriam os objetivos, mas a forma como alcançá-los.

Acusando o socialismo de ser apenas mais uma forma de "coletivismo", Hayek condenou a ideia de "abolição da propriedade privada dos meios de produção e a criação de um sistema de economia planificada" considerando-os uma forma de ameaça a outros valores. Assim, para Hayek, "o debate sobre o socialismo era em grande parte uma discussão sobre meios e não sobre fins embora a questão implique também saber se os diferentes fins do socialismo poderão ser alcançados simultaneamente". Citando Adam Smith, escreveu que o controle dos meios de produção faz com "que os governos para se manterem sejam obrigados a se tornar opressores e tirânicos" (HAYEK, 1990, p.55-63). Foi essa linha de raciocínio que ele desenvolveu durante toda a obra: o sistema socialista, marcado pelo planejamento da economia, produz autoritarismo.

Novamente, o autor de $O$ Caminho da Servidão buscou se diferenciar dos excessos do liberalismo econômico da Escola de Manchester, fazendo uma crítica própria ao socialismo: "é importante não confundir oposição a essa espécie de planejamento com uma atitude dogmática de laissezfaire", uma vez que "em nenhum sistema racionalmente defensável seria possível o Estado ficar sem função".

De acordo com o filósofo austríaco, não se trata de escolher entre o socialismo e o laissezfaire. Para ele, o Estado deve agir na criação de normas para regular a concorrência e assumir a execução de determinadas atribuições. Exaltando a competição como a melhor forma de organização econômica, escreveu que "para a concorrência funcionar de forma benéfica seria necessária a criação de uma estrutura legal cuidadosamente elaborada, e que nem as normas legais existentes, nem as do passado, estão isentas de falhas graves". E, além disso, recusando qualquer tentativa de controle de preços ou da produção como ocorre no socialismo, afirmou que "a manutenção da concorrência tampouco é incompatível com um amplo sistema de serviços sociais" (HAYEK, 1990, p.55-63).

Do ponto de vista do campo liberal clássico, portanto, Hayek destacou-se por apresentar uma crítica ao crescimento do papel do Estado nas economias capitalistas que agradava os críticos do New Deal nos Estados Unidos. Essa posição, contudo, não deixava de apontar o que percebia como certos exageros da política do laissez-faire, elemento importante para o sucesso da mensagem em um país ainda aturdido pelos efeitos da crise econômica. Essa é a grande força de O Caminho da Servidão e que transformou Hayek, como veremos agora, em uma importante liderança do liberalismo econômico e referência para o movimento anti-New Deal no pós-1945.

\section{Hayek nos Estados Unidos}

Com o sucesso de seu livro, Hayek passou a ser convidado para dar palestras em diferentes países. Nos Estados Unidos, o filósofo austríaco era cobiçado principalmente pelos grupos 
empresariais. Sua fama despertou o interesse das elites econômicas temerosas do comunismo e do avanço do programa do New Deal.

Vale ressaltar que esse é o período das maiores greves da história do país. Entre novembro de 1945 e junho de 1946, mais de três milhões de trabalhadores dos mais diferentes setores da economia americana - da indústria automobilística à produção de aço e carvão - cruzaram os braços. O fortalecimento do movimento sindical somado ao aumento sem precedentes do papel do Estado na economia durante a guerra compeliam os empresários a se mobilizarem contra o New Deal. E, neste contexto, o sucesso de Hayek aparecia como uma esperança de reversão do cenário político.

Em março de 1945, Hayek encontrou-se com empresários em Detroit ${ }^{13}$. Na palestra, Hayek apresentou sua ideia de promover um "novo liberalismo" ${ }^{14}$. Para uma plateia inquieta e preocupada, o filósofo prometia um "liberalismo vivo" capaz de disputar no campo da utopia com as ideias da esquerda, em especial o socialismo. Em tom professoral, anunciava uma filosofia viva, um liberalismo econômico novo, capaz de convencer amplos setores da sociedade. Para uma elite econômica frustrada com as iniciativas anti-New Deal da década anterior, suas palavras soavam como música.

Segundo Hayek, o "velho liberalismo (...) entrou em decadência pelos próprios erros", uma vez que incorreu em dois equívocos básicos. O primeiro, a ideia de que toda ação ou interferência do governo na economia é ruim. E, o segundo, a visão de combate a toda atividade estatal, usando "de forma perigosa a palavra socialismo para quase todo tipo de ação do Estado que você considera tola ou que você não concorda".

A partir daí, defendeu a formulação de um conjunto de princípios que distinga as áreas legítimas e ilegítimas para uma intervenção do governo. Para ele, era necessário acabar com as posições reducionistas de "a favor do Estado" ou "contra o Estado" simplesmente, sendo importante debater em que áreas o governo deveria agir ou não. "Temo que a causa da liberdade" se perca se, por desconfiança do governo, considerarmos tudo uma usurpação da responsabilidade individual. "Não podemos acreditar que o governo não deva fazer nada". Precisamos, sim, "estabelecer o que é bom que o Estado faça, o que é necessário", e o que não é, "onde sua interferência nos assuntos econômicos é perigosa". Essa é a grande tarefa de O Caminho da Servidão, frisou.

Para Hayek, no entanto, a tarefa de reformulação do liberalismo econômico demandaria tempo, pois "movimentos intelectuais demoram a dar frutos, já que precisam dominar a opinião pública e determinar os futuros desenvolvimentos". Apesar disso, a missão era urgente, pois: "não há dúvida que nas últimas duas gerações, o principal movimento intelectual, a principal influência veio de pessoas com uma filosofia oposta a que acredito".

Suas últimas palavras resumem o sentimento daqueles homens ali reunidos: na batalha contra o socialismo, o liberalismo econômico perdia de goleada. Mas esse jogo, aos poucos, começava a virar.

\section{Os primeiros contatos}

Hayek passou cinco semanas nos Estados Unidos, visitando universidades e se reunindo com empresários. Em Nova Iorque, um evento simbolizou o novo momento para Hayek: de

\footnotetext{
13 A palestra de Hayek no Clube de Economia de Detroit está presente no discurso "The Road to Serfdom", Michigan. 23 de abril de 1945. Arquivo Hayek. Caixa 106. 35 pags.

14 Como explicado na nota 13, o sentido aqui é de defesa dos princípios do livre mercado.
} 
professor desconhecido na London School transformou-se em referência para um movimento internacional em formação. Em um domingo de manhã, no famoso The Town Hall, mais de três mil pessoas o aguardavam. Com todos os ingressos esgotados, havia pessoas do lado de fora do edifício, frustradas por não conseguirem ouvir o especialista em teoria econômica.

Hayek só soube da grandiosidade do evento no dia. Alguns anos mais tarde, contou que se soubesse com antecedência teria desistido. Na hora da palestra, aflito, pediu para falar por apenas 45 minutos. "Não, você precisa falar por uma hora", lembrou Hayek. "Sobre o que eu devo falar?", questionou. "O título de sua palestra" (The Rule of Law in International Affairs), foi a resposta. "Meu Deus, eu nunca pensei sobre isso. Eu não vou conseguir", respondeu um inseguro Hayek.

Este evento o marcou definitivamente. De professor de turmas reduzidas e especializadas da área acadêmica para o intelectual popular com trânsito no mundo empresarial. Os contatos que estabeleceu com empresários e intelectuais do país foram fundamentais para a sua iniciativa política mais importante: a formação de uma rede internacional de instituições em defesa das ideias do livre-mercado.

\section{A rede a favor do livre mercado}

Em suas memórias e biografias, importantes empresários norte-americanos apontaram $O$ Caminho da Servidão e a viagem de Hayek ao país como fatores-chave para suas formações políticas e intelectuais. Escolhemos aqui a trajetória de um indivíduo para ilustrar: Leonard Read.

Nascido em Michigan, em 1898, Leonard Read ficou famoso por sua atuação como empresário e ideólogo em defesa do livre-mercado. Entre os adeptos do liberalismo econômico, seu nome é lembrado com admiração por seu papel precursor na fundação de uma instituição de promoção das ideias do livre-mercado, a Foundation for Economic Education (FEE) e por seu bestseller I, Pencil.

Mas nem sempre foi assim. Em 1932, Read era o chefe da divisão oeste da Câmara de Comércio dos Estados Unidos, atuando em defesa das medidas que iriam compor o National Recovery Act (NRA), uma das bases do New Deal. Sua mudança política e intelectual aconteceu ainda na década de 1930. Para isso, dois fatores foram primordiais. O primeiro, a influência de William C. Mullendore, vice-presidente da Southern California Edison Company. Secretário de Comércio do governo Herbert Hoover, Mullendore se tornou nas décadas seguintes um participante destacado do movimento conservador. Para Read, foi depois de um dia de conversa com Mullendore que ele se converteu em um defensor do liberalismo econômico. O segundo fator, o contato com as obras do economista francês Frédéric Bastiat (1801-1850), que consolidou nele a crença na necessidade de pregar as ideias do liberalismo econômico (NASH, 2006, p. 28-29).

Nesses anos, enquanto os Estados Unidos lutavam no exterior contra o fascismo, o inimigo para Read era outro: o crescimento das atribuições do governo do seu país. Desde os anos da Grande Depressão, com os programas do New Deal, passando pelas exigências do esforço de guerra, o Estado americano aumentou bastante suas funções. Contra isso, Leonard Read se engajou intensamente para difundir sua crença no livre-mercado, dedicando-se a inúmeras atividades. Em apenas uma delas, um grupo organizado por ele, chamado Panfletários (Pamphleteers), reuniu três mil membros. O trabalho consistia no envio pelo correio de obras de autores liberais clássicos.

Em 1946, Leonard Read fundou a Foundation for Economic Education (FEE). Estabelecida em Nova Iorque, na pacata e arborizada Irvington-on-Hudson, a FEE é considerada uma instituição precursora para o movimento conservador norte-americano. Seu objetivo era claro: promover as 
ideias do liberalismo econômico na sociedade americana. Entre seu público principal estavam políticos, professores, estudantes e empresários. A ideia era "educar os agentes políticos e a sociedade em geral sobre as virtudes da economia de livre mercado". Para isso, nomes influentes na mídia e nas universidades foram convidados, como Henry Hazlitt, economista e jornalista do The New York Times e da Newsweek; Fred R. Fairchild, professor de economia da Universidade de Yale; Claude Robinson, presidente do Opinion Research Institute ${ }^{15}$. Anos depois, Milton Friedman definiu a FEE como "uma das raras organizações defensoras do livre mercado na época [final dos anos 1940]" (FRIEDMAN \& FRIEDMAN, 2012, p.152).

Desde o início, a FEE contou com o apoio de importantes empresários do país, como: Jasper Crane (Du Pont Company), H.W. Luhnow (William Volker Fund), Charles White (Republic Oil Corporation), Donaldson Brown (General Motors) e David Goodrich (Goodrich and Company). No primeiro ano, a FEE arrecadou $\$ 254.000$ (em torno de $\$ 2,5$ milhões em valores de hoje). Nada mal para uma organização que dava seus primeiros $\operatorname{passos}^{16}$.

No entanto, essas iniciativas não impediam que Read sentisse uma certa frustração com o que julgava ser um avanço das ideias do socialismo nos EUA e no mundo. Para ele, os defensores do livre mercado perdiam a disputa de ideias. Nas suas palavras, "[havia] poucas pessoas no mundo que entendem e podem explicar as ideias opostas ao socialismo, ou seja, a defesa do livre mercado, da propriedade privada e da filosofia do governo limitado" (NASH, 2006, p. 29).

Neste momento, Hayek e seu livro apareceram como uma solução para Read. Os dois viraram amigos durante a viagem do austríaco aos Estados Unidos. Tornaram-se, além disso, aliados no projeto de promoção das ideias do livre-mercado. O empresário foi um dos principais apoiadores da iniciativa de Hayek de constituir uma organização internacional de indivíduos e instituições a favor do liberalismo econômico.

\section{A Sociedade Mont Pelerin}

Em abril de 1947, aos pés dos Alpes suíços, Hayek fundou a Sociedade Mont Pelerin (SMP). Junto com ele, outros 39 indivíduos, entre eles intelectuais, jornalistas e empresários, participaram da iniciativa. A ideia da organização era formar uma rede internacional de apoiadores e promover a ideologia do livre mercado.

No ano anterior, ao escrever uma carta convidando para participar da iniciativa, Hayek escreveu:

Nas conversas que tive durante os últimos dois anos com amigos em diferentes países, percebi um forte desejo de maior contato entre as pessoas que se preocupam fortemente com as possibilidades de se preservar uma civilização livre, e que sentem que não apenas toda a relação entre a coerção governamental e as liberdades individuais requerem um reexame, mas também as visões dominantes da história recente deverão ser revisadas para que as crenças predominantes e equívocos não nos conduzam ainda mais em uma direção totalitária ${ }^{17}$.

A Sociedade Mont Pelerin era a resposta de Hayek ao que percebia ser a ameaça de um "caminho para a servidão" nos países europeus e nos Estados Unidos. Um dos participantes mais

15 Programa divulgado em 15 de maio de 1949. Arquivo Hayek Papers. Caixa 20. Pasta 1. Correspondências. FEE.

16 Arquivo Hayek Papers. Caixa 20. Pasta 1. Foundation for Economic Education.

17 Correspondência enviada por Hayek para os convidados do Encontro de 1947. 28 de dezembro de 1946. Arquivo Hayek Papers. Caixa 61. Pasta 8. 
famosos do primeiro encontro da organização, o economista da Universidade de Chicago, Milton Friedman, então um jovem professor universitário ainda desconhecido, descreveu assim o encontro: "Hayek e nós sentíamos que o mundo caminhava para a planificação, e de alguma forma deveríamos desenvolver uma empreitada intelectual para lutar contra esse movimento ${ }^{18}$ ".

Dos 39 fundadores, de dez países diferentes, vinte e oito eram profissionais do meio acadêmico. Desses, a maioria (vinte) era composta por economistas. Havia ainda três jornalistas, além de historiadores, cientistas políticos, filósofos e juristas ${ }^{19}$. A Sociedade Mont Pelerin foi capaz de reunir, já no momento de seu surgimento, as principais figuras do período identificadas com as ideias do liberalismo econômico: ingleses, como Lionel Robbins, John Jewkes e Michael Polanyi; emigrados austríacos, como Ludwig von Mises, Fritz Machlup, Karl Popper, e claro o próprio Hayek; os estadunidenses Henry Hazlitt, Frank Knight, Milton Friedman, Aaron Director e George Stigler; da Alemanha, Wilhelm Röpke e Walter Eucken; franceses, como Maurice Allais e Bertrand de Jouvenel; além de outros europeus. Em comum, compartilhavam a defesa de certos princípios do liberalismo econômico e o sentimento de que o mundo ocidental vivia uma crise com a ameaça socialista e/ou keynesiana às liberdades individuais.

Inicialmente, a Mont Pelerin definia-se como um grupo de estudos, voltada a proporcionar o "debate de grandes questões contemporâneas entre profissionais dos mais diversos campos" com o objetivo de "renovar e ressuscitar o liberalismo econômico". Com o passar dos anos, a organização cresceu e se tornou referência para o surgimento de instituições similares, mas mais voltadas à intervenção no debate público.

Essa rede internacional constituída por Hayek contou com a participação e o apoio ativo de Leonard Read e sua Foundation for Economic Education. A fundação nova iorquina, criada um ano antes do primeiro encontro da Mont Pelerin, foi importante para estreitar relações entre os indivíduos que participarão da iniciativa de Hayek. A FEE organizou uma série de encontros - seminários, conferências e jantares - que serviu para fomentar o desenvolvimento de uma rede de estudiosos e apoiadores da causa.

A ligação entre a FEE e a Mont Pelerin era bastante estreita. Muitos participantes da SMP realizavam seminários, publicavam livros e/ou trabalhavam na fundação de Read. Esse é o caso de Mises. Sete anos após emigrar para os Estados Unidos, um dos mais destacados intelectuais da Escola Austríaca de Economia passava por grandes dificuldades financeiras antes de ser contratado pela FEE. Sem conseguir emprego em uma universidade americana, o economista austríaco tornou-se conselheiro da FEE.

Além da organização de Read, há outras instituições norte-americanas que apoiaram a Mont Pelerin, como o William Volker Fund, comandado por Harold W. Luhnow. O empresário que conheceu Hayek na palestra no Clube de Economia, em Detroit, descrita nas páginas anteriores, foi bastante atuante no apoio à rede formada por Hayek. Sob seu comando, nas décadas de $1940 \mathrm{e}$ 1950, o fundo desembolsou mais de \$1 milhão por ano para pagar despesas relacionadas às atividades de promoção das ideias do liberalismo econômico. Durante os seis primeiros anos da organização da Mont Pelerin (1947-1953), o fundo pagou todas as anuidades dos membros norte-americanos, arcando ainda com suas viagens para os encontros na Europa. Em muitos momentos, pagou também os custos das despesas dos representantes europeus, possibilitando a realização das

\footnotetext{
18 Video: “Batalla por Economía Mont Pelerin y Escuela de Chicago 1947-1950s", disponível em https://www.youtube.com/watch?v=Hqtmqq0jx7Y.

19 Sobre o primeiro encontro da organização: documento Mont Pelerin General 1947. Arquivo da Sociedade Mont Pelerin. Caixa 5. Pasta 1
} 
reuniões da instituição.

A partir dos anos 1950, membros da Mont Pelerin passaram a contribuir para a fundação de inúmeros think tanks, principalmente nos EUA e na Europa, com o objetivo de intervir no debate público e influenciar governos a adotar uma agenda de reformas afinadas com o livre-mercado. Nos anos 1970, essa rede internacional ampliou-se para a América Latina e Ásia.

Defendemos no artigo, portanto, que a iniciativa de Hayek foi um importante guarda-chuva para o desenvolvimento de instituições (think tanks) de promoção do livre mercado. E essa rede, constituída a partir da Mont Pelerin, só foi possível graças ao apoio crucial de empresários norteamericanos como Leonard Read e Harold Luhnow.

\section{Conclusão}

Nos Estados Unidos, em meados do século XX, a crença no governo como instrumento para resolver os problemas da economia e garantir o bem-estar dos cidadãos afirmava-se com força. A coalizão do New Deal, construída a partir dos anos 1930, manteve-se por quatro décadas. Esse contrato social, negociado entre o governo federal e os cidadãos norte-americanos em nome de um bem-estar geral, foi uma herança do governo Roosevelt, preservada por democratas e republicanos. A ideia de que o Estado era o responsável por proteger os cidadãos da crise econômica e do desemprego, por regular a economia com a adoção de políticas para estimular o crescimento e por prover serviços públicos básicos tornou-se um consenso no país no imediato pós-guerra.

Consenso. E não unanimidade. As sementes da contestação a esse papel do governo já estavam presentes. As elites políticas, econômicas e intelectuais críticas ao New Deal, contudo, não possuíam força para avançar um projeto alternativo. O lançamento de Caminho da Servidão começou a mudar esse panorama. Essas elites viram em Hayek um aliado precioso. Suas ideias eram populares - ou pelo menos mais difundidas do que a agenda pró-livre mercado tradicionalmente era - e sua proposta de uma reformulação do liberalismo econômico atendia às necessidades do contexto político e econômico do período.

Ao longo das décadas de 1950 e 1960, as críticas a um Estado grande e interventor e a defesa do mercado como mais importante alocador de recursos da economia ganharam adeptos gradualmente. Somado a isso, instituições de defesa de uma agenda liberal econômica espalharamse pelo país. E, a partir dos anos 1970, quando as políticas keynesianas não conseguiram oferecer respostas para as dificuldades econômicas enfrentadas, a agenda crítica ao New Deal ganhou espaço.

Importante dizer que a ascensão política das ideias do liberalismo econômico no país, cujo marco mais importante é a chegada à presidência do republicano Ronald Reagan, em 1981, faz parte de um contexto internacional mais amplo. Nesse artigo, buscamos examinar a importância de Hayek para o fortalecimento de uma agenda a favor do livre mercado nos Estados Unidos. $\mathrm{O}$ seu $O$ Caminho da Servidão, assim como sua rede transnacional de indivíduos e instituições a partir da Sociedade Mont Pelerin, com o forte apoio das elites econômicas norte-americanas, foram fundamentais para avançar o movimento de contestação às políticas econômicas e sociais do New Deal.

Para concluir, defendemos que a trajetória de Hayek, o apoio dos intelectuais e empresários norte-americanos e a constituição de uma rede internacional a partir da Sociedade Mont Pelerin são fundamentais para compreender a história da ascensão das ideias a favor do livre mercado na segunda metade do século XX. Novos estudos são bem-vindos para mapear e explicar melhor 
como essa comunidade transnacional produziu impactos nas políticas públicas dos governos nacionais no período, em especial nos Estados Unidos. Uma iniciativa que teve início com um livro despretensioso, com alguns encontros entre intelectuais e empresários e a criação de uma instituição com apenas 39 participantes tornou-se um movimento bem mais amplo décadas depois. Atualmente, apenas uma das organizações que compõem a Sociedade Mont Pelerin, o think tank norteamericano Atlas Foundation é responsável por coordenar uma rede de 500 instituições em 98 paí$\operatorname{ses}^{20}$. Esse dado nos dá a dimensão do tamanho do desafio dos estudos que pretendem conhecer um pouco melhor a história da expansão política e intelectual do liberalismo econômico no pós1945.

\section{Fontes}

Arquivo Hoover Institution (Universidade de Stanford):

Fundo Foundation for Economic Education

Fundo Friedrich von Hayek

Fundo Fritz Machlup

Fundo Sociedade Mont Pelerin

Archive.org - Entrevista de Hayek em Nobel prize-winning economist oral history transcript

\section{Referências bibliográficas}

BURNS, Jennifer. Goddess of the Market: Ayn Rand and the American Right. New York: Oxford University Press, 2009.

COHEN, Lizabeth. Making a New Deal: Industrial Workers in Chicago, 1929-1939. New York: Cambridge University Press, 1990.

FRIEDMAN, Milton \& FRIEDMAN, Rose. Two lucky people: memoirs. Chicago: The University of Chicago Press, 2012.

HAYEK, Friedrich August von. Studies in Philosophy, Politics and Economics. New York: Simon \& Schuster, 1967. . O caminho da servidão. Rio de Janeiro: Instituto Liberal, 1990.

NASH, George. H. The conservative intellectual movement in America since 1945. Delaware: ISI Books, 2006. 2009.

Reappraising the Right. The past \& future of American conservatism. Delaware: ISI Books,

PHILLIPS-FEIN, Kim. Invisible hands: the making of the conservative movement from the New Deal to Reagan. New York: W.W. Norton \& Company, 2009.

Artigo recebido em: 30/10/2019

Artigo aceito em: 17/12/2019

20 Disponível em https://www.atlasnetwork.org/partners/global-directory. 